\title{
EDUCAÇÃO E TRABALHO: É POSSÍVEL UMA LEITURA MARXISTA SOBRE OS DISCURSOS E PRÁTICAS EDUCACIONAIS NO CAMPO?
}

\author{
Elianeide Nascimento Lima ${ }^{1}$ \\ Luiz Bezerra Neto ${ }^{2}$
}

\begin{abstract}
RESUMO:
O presente texto resulta de reflexões e discussões em torno das bases filosóficas e políticas presentes e inspiradoras dos discursos, práticas e propostas educacionais para o campo. $\mathrm{O}$ pano de fundo que sustenta as reflexões aqui apresentadas é constituído pela discussão sobre os fundamentos de uma pedagogia socialista, articulado às categorias educação, trabalho e movimento social. Assim, discute-se se é possível uma leitura marxista sobre os discursos e práticas educacionais no campo como possibilidade de uma pedagogia socialista a partir das experiências implementadas no seio da revolução russa de 1917 que é resgatada como forma de oferecer subsídios à discussão em torno de propostas alternativas de educação do campo, no Brasil. No texto, discutimos a necessidade de se revitalizar a discussão em torno dessas práticas a partir de questões fundamentais e necessárias que remetem aos ideais originais do socialismo. Ao final discutimos a tendência ao ecletismo teórico e metodológico assumido pelo "movimento por uma educação do campo", bem como a concepção pragmática da realidade, que se encontra nas propostas educacionais vigentes e a necessidade de revisitar os postulados das pedagogias socialistas iniciais como forma de identificar a pauta necessária que deverá compor a agenda de qualquer forma de educação popular.

Palavras-chave: Educação e trabalho, Pedagogia socialista, Práticas educacionais do campo, Materialismo histórico dialético.
\end{abstract}

\section{EDUCATION AND WORK: IS IT POSSIBLE A MARXIST READING OVER THE DISCOURSES AND PRACTICES OF RURAL EDUCATION?}

\begin{abstract}
:
This text is the result of reflections and discussions on the philosophical and political bases that inspire and are present in discourses, practices, and educational proposals to the countryside. The background that support the reflections here conveyed consists on the discussions about a socialist pedagogy's foundations, linked to the categories education, work and social movement. Thus, we discuss whether it is possible a Marxist reading on the discourses and practices of rural education, as a possibility of a socialist pedagogy founded in the experiences implemented by the Russian revolution of 1917, which is rescued as a way to offer subsidies to the discussion around alternative proposals on rural education in Brazil. We discuss the need to revitalize the debate on these practices, based on fundamental and needful issues that refer to the original ideals of socialism. Finally we discuss the theoretical and methodological trend of eclecticism assumed by the "movement for rural education", as well as the pragmatic conception of reality, which is prevailing in the educational proposals and we point out the need to revisit the postulates of the former socialist pedagogies as a means of identifying the fundamental points that should be on the agenda of any form of popular education.

Keywords: Education and work, socialist pedagogy, educational practices from the countryside, historical and dialectical materialism.
\end{abstract}




\section{Introdução}

A idéia de discutir se é possível uma leitura marxista sobre os discursos e práticas educacionais no campo brasileiro surgiu durante as aulas de trabalho e educação, no programa de pós graduação, mas evidenciou-se mais necessária após a participação no I encontro internacional de educação do campo realizado em agosto de 2010, em Brasília, momento em que observamos que boa parte dos participantes se contrapunham ao marxismo e defendia um pressuposto culturalista para se trabalhar com a educação do camponês.

A partir de então resolvemos revisitar as obras de Pistrak, Makarenko e do próprio Marx, no sentido de se apropriar de suas contribuições para analisar a educação que hoje se pratica no campo brasileiro, bem como as propostas dos movimentos sociais que atuam no campo e que pretendem construir um projeto de educação para o setor.

Sendo assim, podemos afirmar que um aspecto fundamental para discutir a educação dos trabalhadores rurais que ainda é pouco explorado, é a concepção predominante de educação nas práticas educacionais no campo, dado que alguns movimentos sociais ligados aos trabalhadores do campo dizem apresentar tendências socialistas em suas concepções educacionais, porém essa tem soado como uma afirmação muito vaga, uma vez que tal afirmação nem sempre destaca veios cruciais como as relações entre educação e trabalho, educação e escola, educação e prática pedagógica, educação e política, educação e organização da classe trabalhadora. Por outro lado, temos percebido que muitas vezes, por trás do anúncio de uma concepção socialista de educação são encontrados discursos e práticas ecléticas e pragmáticas que, algumas vezes se aproximam e doutras se distanciam de modelos socialistas de educação.

É nesse sentido que o presente texto propõe a abordagem do tema educação $e$ trabalho tendo como pano de fundo, em particular, as contribuições dos educadores russos Moisés Mikhaylovich Pistrak (1888-1937), e de Anton Semionovich Makarenko (18881939), e de modo mais amplo a visão histórico-dialética de educação. Nesse sentido, propostas educacionais pensadas para e junto a classe trabalhadora que habita no campo serão visitadas, como forma de discutir e entender as direções ou tendências gerais assumidas nas duas últimas décadas, no Brasil.

\section{Os Movimentos sociais e a pedagogia socialista: a práxis educacional de M. M. Pristak e de Anton Semionovich Makarenko}

Para discutir a educação nos movimentos sociais, faz-se fundamental que adotemos o método mais adequado, que entendemos ser o materialismo histórico-dialético. Nesse caso é necessário distinguir o método de exposição formalmente do método de pesquisa, dado que para Marx a pesquisa tem de captar detalhadamente a matéria, analisar as suas várias formas de evolução e rastrear sua conexão íntima. Só depois de concluído esse trabalho é que se pode expor adequadamente o movimento real (Marx, 1996, p. 140), e assim, entendendo o movimento real, compreender o mundo em que se vive.

Para tanto, temos que compreender que o conhecimento, como processo e como resultado de um fazer próprio do ser humano, é a forma pela qual o homem expressa abstratamente as relações que mantém com o mundo circundante e com outros homens. É necessário compreender ainda, que como produto da existência humana, as formas assumidas pelo conhecimento transformam-se historicamente, estando submetidas às mesmas determinações históricas que as demais idéias produzidas pelos homens. Nesse caso, as idéias passam a se constituir na representação daquilo que o homem faz da sua maneira de viver, da forma como se relaciona com outros homens, do mundo que o circunda e das suas próprias necessidades. 
Em A Ideologia Alemã, Marx e Engels afirmam que a

produção de idéias, de representações e da consciência está em primeiro lugar direta e intimamente ligada à atividade material e ao comércio material dos homens, é a linguagem da vida real. São os homens que produzem as suas representações, as suas idéias, etc., mas os homens reais, atuantes e tais como foram condicionados por um determinado desenvolvimento das suas forças produtivas e do modo de relações que lhe corresponde, incluindo até as formas mais amplas que estas possam tomar. (...) Não é a consciência que determina a vida, mas sim a vida que determina a consciência (Marx e Engels, s/d, p. 25-26).

Nesse sentido, para apreendermos a realidade em que vivemos, o melhor caminho é não partir "daquilo que os homens dizem, imaginam e pensam, nem daquilo que são nas palavras, no pensamento, na imaginação e na representação...; parte-se dos homens, da sua atividade real". Dado que "Não é a consciência que determina a vida, mas sim a vida que determina a consciência" (Marx e Engels, p. 25-26), o que nos leva a inferir que mais importante do que os discursos dos movimentos, governantes ou sociedade em geral é sua prática político-social.

Esta observação é importante porque muitas vezes, em nome de uma pseudo tendência revolucionária, alguns movimentos se apropriam de pressupostos pragmáticos e idealistas, embora não seja esta tendência, privilégio dos movimentos de nosso tempo, visto que no Anti-Düring, Engels já apontava a confusão e inversão idealista cometida por Dühring que, dizendo-se materialista, acabava fazendo uma inversão dos princípios filosóficos aos quais recorria.

Para Engels:

Quando ele fala de princípios, refere-se a princípios de pensamento independentes, não deduzidos do mundo exterior, e de princípios formais, derivados, aplicáveis à natureza e ao mundo dos homens ... Mas, de onde tira o pensamento esses princípios? Os esquemas lógicos só podem referir-se a formas conceituais... trata-se apenas das formas do que existe, do mundo exterior... Mas isto inverte toda a relação estabelecida: os princípios já não são o ponto de partida da investigação, mas seus resultados finais; não se aplicam à natureza e à história humana...; não é a natureza e o mundo dos homens que se regem pelos princípios, mas só estes é que têm razão de ser quando coincidem com a natureza e com a história. Nisto consiste a verdadeira concepção materialista das coisas, o oposto do que afirma o Sr. Dühring, que é idealista e cuja concepção inverte todas as coisas, construindo o mundo real partindo da idéia, de uma série de esquemas, planos ou categorias existentes e de valor eterno e anterior à existência do mundo" (Engels, 1979, p. 31-32).

Este esclarecimento se fez necessário para demonstrar a importância da adoção do materialismo como princípio explicativo do mundo e como princípio para o conhecimento, como trabalhados por Marx e Engels tendo sido, assim exposta por Engels no AntiDühring:

A unidade do mundo não consiste no seu ser... A unidade real do mundo consiste na sua materialidade e esta última está provada... por um longo e laborioso desenvolvimento da filosofia e das 
ciências naturais... O movimento é o modo de existência da matéria. Nunca e em parte alguma houve nem poderá haver matéria sem movimento... Matéria sem movimento é impensável do mesmo modo que movimento sem matéria... Mas, se se pergunta, depois disso, o que é o pensamento e a consciência, de onde provém, conclui-se que são produtos do cérebro humano e que o próprio homem é um produto da natureza, o qual se desenvolveu no seu ambiente e com ele; daí se compreende por si só que os produtos do cérebro humano... são igualmente produtos da natureza, não estão em contradição, mas sim em correspondência com a restante conexão da natureza (Apud LENINE, 1982 p. 8-9).

Somente assumindo uma postura materialista, portanto, revolucionária é que se pode pensar nas transformações que os movimentos sociais tem buscado, dado que esta concepção é revolucionária e como podemos perceber no Prefácio à Contribuição à Crítica da Economia Política de Marx:

Em certo estágio de desenvolvimento, as forças produtivas materiais da sociedade entram em contradição com as relações de produção existentes ou, o que é a sua expressão jurídica, com relações de propriedade no seio das quais se tinham movido até então. De formas de desenvolvimento das forças produtivas, estas relações transformam-se no seu entrave. Surge então uma época de revolução social. A transformação da base econômica altera, mais ou menos rapidamente, toda a imensa superestrutura. Ao considerar tais alterações é necessário sempre distinguir entre a alteração material [...] e as formas jurídicas, políticas, religiosas, artísticas ou filosóficas, em resumo, as formas ideológicas pelas quais os homens tomam consciência deste conflito, levando-o às últimas conseqüências (Marx, 1983, p. 24-25).

Tal qual Marx, alguns movimentos sociais, como o MST, por exemplo, afirmam fazer uma opção pela ação revolucionária. Esta ação revolucionária, no entanto, não pode excluir a alternativa reformista, pois as reformas, como afirma Lombardi

são como que um resultado "colateral" da luta revolucionária das massas. Mesmo quando as reformas não são o resultado imediato da luta revolucionária dos trabalhadores, as concessões reformistas ocorrem sob a pressão das exigências das massas populares, e não como uma dádiva das classes dominantes. Em outras palavras, não se trata de negar as reformas, mas de trabalhá-las como uma das táticas da revolução. Nessa perspectiva tática, por um lado é necessário desmascarar o reformismo que dilui a revolução nas reformas; por outro lado, é lutar contra um revolucionarismo esquerdista infantil e que ergue uma barreira intransponível entre as reformas e a revolução, perdendo de vista que a tática deve ser colocar em ação os mecanismos necessários para o avanço rumo aos objetivos estratégicos da luta revolucionária (LOMBARDI, 2010, 211). 
Ao tratar da ação revolucionária proposta por Marx, José Claudinei Lombardi considera, que

O fundamental é não perder de vista que se trata de um conceito central na abordagem marxista e expressa o processo de ruptura e transformação das estruturas econômicas, sociais, políticas e ideológicas, desembocando na formação de novas estruturas e de um novo regime. Marx e principalmente Engels destacaram que uma característica da revolução é a violência, geralmente decorrente das lutas e conflitos que se abrem entre as classes sociais antagônicas e que acabam levando ao uso da força e à beligerância entre aqueles que assumem e os que deixam o poder em decorrência dos movimentos revolucionários (LOMBARDI, 2010, p. 211).

É a partir dessa concepção em que a luta entre o capitalista e o assalariado que o pensamento de Moisés Mikhaylovich Pistrak e Anton Semionovich Makarenko tem ganhado maior visibilidade e aparecido no meio acadêmico brasileiro nas últimas três décadas, sobretudo, pela influência do Movimento dos Trabalhadores Rurais Sem Terra, que tem divulgado através da editora "expressão popular", o pensamento desses educadores. Assim sendo, é importante observar que uma análise inicial das repercussões, no campo educacional, das propostas marxistas, nos leva a considerar pertinente a indicação de Soares, de que:

\begin{abstract}
A implosão das sociedades do leste europeu veio reforçar pelo menos três grandes correntes de pensamento, ainda que contraditórias entre si: a) a que critica o marxismo a partir de uma ótica liberal para legitimar o capitalismo; b) a que critica o marxismo sugerindo uma revisão de paradigmas sem propor a adesão ao capitalismo tardio; c) a que procura desenvolver o marxismo numa perspectiva histórico-crítica (SOARES, 1997, p. 145).
\end{abstract}

Essa terceira corrente aponta para horizontes ampliados, principalmente por considerar como fatos relevantes e que necessitam ser ressaltados: o contexto social, político e histórico das propostas educacionais. Em outras palavras, esta suposta obviedade nos ajuda a destacar que as tendências atuais no campo educacional não podem ser simplesmente transposições de um lócus específico para outro. Há que se verificar o contexto em que determinadas propostas foram gestadas e aplicadas, a fim de não se cair no equívoco e ingenuidade política de adoção de ações e reflexões desvencilhadas do tecido social originário. Desse modo, pensar uma prática educacional no campo, dentro da malha de relações específicas do campo, implica em perscrutar especificidades e determinantes do ser e do estar no campo, sem perder de vista algo que consideramos fundamentais, ou seja, as categorias de totalidade e de contradição, fundamentais para compreender qualquer realidade social.

Queremos, com isso, declarar que, em termos de uma dialética marxista, ficar preso a contextos passados não ajuda a divisar os contextos atuais; porém, por coerência, os contextos passados trazem, em si, o novo, isto é, possibilidades de se transmudarem a partir das demandas do presente e por isso mesmo, lições que não podemos perder de vista, se quisermos avançar politicamente e socialmente na construção de uma sociedade em que a exploração do homem pelo homem possa ser superada. Em relação à realidade do campo, no Brasil, identificamos situações de exploração e de expropriação de direitos básicos. Neste sentido, constatamos que a opressão apenas muda de território geográfico e de tempo 
cronológico. Ao tratarmos da educação, podemos verificar que os idiomas pedagógicos são diferenciados e apresentam marcas e contextos específicos em função das demandas ambientais, modo de vida e de produção, tempo e espaço vividos pelos trabalhadores. Em que pesem os contextos diferenciados, há que se recorrer às experiências forjadas no passado, particularmente na Rússia pós-revolução, a fim de se entender e dimensionar as propostas educacionais do presente. Faz-se necessário, antes de prosseguir, uma breve digressão em torno das propostas de Pistrak e de Makarenko, a fim de consolidarmos as bases de nossa análise em torno das experiências educacionais para os trabalhadores do campo.

É preciso ainda, considerar que as práticas de educação e pedagogia socialistas representaram experiências desenvolvidas por diversos educadores russos, dentro os quais Nadéjda Krupskaya, Pavel Blonsky e Vassili Lunatcharsky. Pistrak e Makarenko, fizeram parte desse grupo de educadores revolucionários da Rússia, na primeira metade do século passado, destacando-se, sobretudo, pela proposição de uma educação que exigia a mudança nos horizontes da escola, no trabalho pedagógico do professor e no papel dos alunos. Em suma, Pistrak e Makarenko preconizam uma proposta de educação voltada para o Trabalho.

Nesse sentido, a busca de uma articulação entre trabalho e educação passou a ser exaustivamente pesquisada e debatida e que no dizer de Lombardi,

\begin{abstract}
Parece haver relativo consenso de que essa análise marxista expressa que "trabalho e educação são atividades especificamente humanas", no sentido de que "apenas o ser humano trabalha e educa" (Saviani, 2007, p. 152). Mas essa articulação entre trabalho e educação, teoricamente, é tratada por Marx e Engels, em A Ideologia Alemã, a partir do entendimento do trabalho como um modo de ser do homem, como meio de produzir sua própria existência. Ao buscarem a distinção do homem dos demais animais expressaram que não é a consciência (ou cultura) que distingue os homens dos outros seres, mas o modo de produção de seus meios de vida, como já foi anteriormente explicitado (LOMBARDI, 2010, 231-232).
\end{abstract}

No texto em que trata sobre os Fundamentos da Escola do Trabalho, Pistrak lança as bases de uma pedagogia socialista. De acordo com Félix, Moreira e Santos:

O texto fundamentos da escola do trabalho não pode ser tomado como manual para os dias atuais, mas sim como um texto instigador para reflexões e construção de ações educativas e teorias pedagógicas correspondentes às necessidades colocadas pela singularidade, particularidade e universalidade presentes em cada escola, em cada comunidade (FÉLIX, MOREIRA e SANTOS, 2007, p. 228).

Esta proposição possibilita uma abertura para o que temos anunciado até aqui, como a necessidade de contextualizar e, mais que isso, entender os contextos atuais, na malha social em que os trabalhadores se encontram. Somente desta forma é que poderemos dimensionar as propostas de Pistrak e de Makarenko para os nossos dias e, sobretudo, aprender com suas contribuições o significado de uma pedagogia socialista para a realidade do campo brasileiro na atualidade.

Para compreendermos os pontos fundamentais da pedagogia socialista, tomando por base o pensamento de Pistrak e de Makarenko, é preciso tomar apreender as bases 
político-educacionais de suas propostas. Para tanto, devermos partir do mesmo pressuposto que eles partiram, ou seja: a educação não se reduz ao ensino.

É neste sentido que Cambi afirma que o modelo pedagógico e educativo elaborado por Marx e Engels

introduziu na pedagogia contemporânea pelo menos duas propostas que podem ser consideradas revolucionárias: a referência ao trabalho produtivo, que se punha em aberto contraste com toda uma tradição educativa intelectualista e espiritualista, e a afirmação de uma constante relação entre educação e sociedade, que se manifesta tanto como consciência de uma valência ideológica da educação como projeção "científica" de uma "sociedade liberada", também no campo educativo (CAMBI, 1999, p. 485).

Assim sendo, a educação deve ser compreendida como uma prática cultural humana que forja subjetividades, modos de agir, pensar, refletir e criar. A educação, como prática humana, tem como lócus o próprio fazer humano no mundo. Onde quer que haja interação entre indivíduos, ali haverá ação educativa, ali haverá um entrelaçamento de forças sociais determinando modos de ser, visões de mundo, crenças, desvelamentos ou acobertamentos de aspectos da realidade. Não há, portanto, necessariamente um momento de ensino formal ou oficial, embora esse momento também faça parte da prática educativa. Em outras palavras, embora a educação não seja reduzida ao ensino, este toma uma dimensão fundamental em nossas sociedades. Desse modo, cabe a análise do papel da escola, seja como reprodutora da ordem vigente e criadora de consciências e indivíduos que meramente se enquadram sob as forças sociais de manutenção, seja como dinamizadora de experiências curriculares que ampliam horizontes conceituais e fornecem instrumentos para a tomada e organização de ações que se contraponham àquelas forças sociais. Outro aspecto fundamental para a compreensão de suas teorias está na constatação de que em uma de suas proposições, Pistrak afirma que educação e fazer humano não apresentam linhas demarcatórias uma vez que o próprio fazer humano já é, em si, uma prática e um reflexo da educação.

Esta constatação nos leva a outra, ou seja, a de que sem uma teoria pedagógica revolucionária não há prática pedagógica revolucionária, ou seja, uma teoria pedagógica reacionária ou conservadora, necessariamente levará a uma prática pedagógica reacionária ou conservadora.

Para tanto, devemos retornar ao próprio Marx, pois, como podemos observar, em sua Crítica ao programa de Gotha, de 1875, no comentário ao item em que se reivindicava a "Interdição do trabalho das crianças, bem como do trabalho das mulheres que causa prejuízo à saúde e à moralidade", Marx assim posicionou-se:

A "proibição geral" do trabalho infantil é incompatível com a existência da grande indústria e, portanto, um piedoso desejo e nada mais. Por em prática esta proibição - supondo-a factível - seria reacionário, uma vez que, regulamentada severamente a jornada de trabalho segundo as diferentes idades e aplicando as demais medidas preventivas para a proteção das crianças, a combinação do trabalho produtivo com o ensino, desde uma tenra idade, é um dos mais poderosos meios de transformação da sociedade atual (MARX, s/d p. 224).

Partindo das observações acima, Pistrak volta seu olhar para o interior das escolas e propõe que toda prática educativa gera e é gerada por uma leitura de mundo. Do ponto de 
vista das forças de manutenção é importante que os discursos pedagógicos embasem práticas pedagógicas que sirvam à aquietação dos trabalhadores; enquanto do ponto de vista dos explorados é fundamental que práticas pedagógicas sirvam à inquietação dos trabalhadores. Os resultados, evidentemente, são díspares. A teoria pedagógica revolucionária não se separa da teoria revolucionária mais ampla que é o materialismo histórico dialético e seu instrumental de análise por meio de categorias como totalidade (tudo se relaciona), transformação, mudança qualitativa, luta dos contrários, materialidade do mundo, matéria antecede consciência, mundo conhecível. É o materialismo histórico dialético que deverá estar na base de práticas pedagógicas que se querem transformadoras;

Ao se decepcionar com as pedagogias até então conhecidas, Makarenko passa a defender a criação de uma pedagogia própria. Uma pedagogia que tinha por base a disciplina e a condenação do culto à espontaneidade infantil. Para ele, a educação socialista deveria formar homens e mulheres trabalhadores e cultos, portanto, os antigos explorados deveriam ser reeducados para assumirem o comando da nova sociedade: a sociedade socialista. Para tanto, era necessário que se criasse uma escola que fosse educadora do povo, ou seja, que possuísse uma prática pedagógica escolar, de um ponto de vista revolucionário, que se assumisse como prática transformadora, ou seja, como práxis que revitaliza a noção de que são os homens que fazem a história.

Educar o povo, portanto, significaria oferecer as ferramentas de análise dos entrelaçamentos sociais a fim de que sejam descortinadas as relações de poder que mantêm sua situação atual e a fim de que os trabalhadores entendam que a mudança do mundo pode ocorrer a partir de suas ações coletivas e conscientes. Educar o povo seria, em primeira instância, deseducá-lo; ou seja, ensiná-lo a desmontar as estruturas de poder que o tornaram passivo e alienado e desvelar as raízes históricas da exploração e das desigualdades, indicando os instrumentos de organização e de auto-organização que levassem ao conhecimento da realidade vigente. A escola, desse modo, não poderia se limitar unicamente a conteúdos pasteurizados, mas deveria redimensionar seu espaçotempo na direção de uma prática que educasse e libertasse.

Para Pistrak, isso seria possível através da inserção da escola nas atividades produtivas, ou seja, a escola deveria estar voltada para o trabalho. Esta é uma asserção fundamental na leitura de Pistrak sobre a escola. Para ele, não há como desvincular educação e prática, não há como desvincular vida escolar de atividade produtiva. Neste sentido, Pistrak propunha que a escola deveria oferecer não só experiências próximas ao cotidiano, mas que trouxesse o cotidiano de produção para o cotidiano da escola. Em outras palavras, propunha que os conteúdos fossem redimensionados a partir das práticas coletivas de produção, o que garantiria um amplo entendimento da realidade enquanto constituída pela forma como os homens transformam a natureza e criam cultura.

Da mesma forma, para Makarenko os fins da educação deveriam ser determinados pelas necessidades sociais em constante transformação histórica, combinando e desenvolvendo as diferentes personalidades no processo de autogestão. Para ele, a escola deveria ser organizada de acordo com os princípios da instrução geral e do trabalho produtivo, retirando a centralidade da sala de aula e transferindo-a para o educando.

Sendo assim a escola deveria estar vinculada ao movimento social e ao mundo do trabalho. Este princípio é uma decorrência do princípio de que educação e trabalho não se desvinculam, sobretudo porque ambos são práticas culturais que criam indivíduos e coletividades, subjetividades e grupalidades. É importante aqui ressaltar que a categoria trabalho, em Pistrak, deve ser entendida como relação social e não simplesmente como produção emprego ou ocupação dentro de um mercado. 
Nessa concepção, trabalho é relação social que produz a base material da existência humana e vai além, produzindo as dimensões estéticas, culturais, artísticas, de lazer (FRIGOTTO, 1987). Neste sentido, ao não desvincular trabalho e educação, e ao preconizar que a escola deve ter no trabalho o seu esteio por meio do qual as experiências curriculares são criadas, e ao entender a categoria trabalho como o modo de ser e de estar dos homens no mundo, transformando a natureza, transformando-se e criando a base material e espiritual da existência, Pistrak consegue redimensionar a ação pedagógica da escola, o seu papel na formação dos indivíduos e dos coletivos. Por conseguinte, os papéis de professor e de aluno também são redimensionados;

Outra característica importante para estes autores era a crença que tinham na autoorganização dos educandos como base do progresso pedagógico na escola. O método pedagógico de Makarenko era um projeto de construção de escola como coletividade, o que significava planejar racionalmente os passos para o funcionamento da autogestão, junto ao coletivo, entendendo que cada criança deveria se transformar no centro da educação e de toda a vida coletiva, que passaria a se desenvolver graças às forças espontâneas de autoorganização dessas crianças.

Como a análise de Pistrak está voltada para as escolas primária e secundária, isto é, para crianças e adolescentes, e por coerência com o método do materialismo histórico dialético, o qual propõe que os homens criam e transformam o mundo e são, portanto, sujeitos de sua própria história, esse educador russo entende que as crianças e os adolescentes, sendo sujeitos ativos, deveriam experienciar a possibilidade de gerir suas próprias vidas. A isto chamou de auto-organização, ponto fundamental em sua pedagogia socialista (TRAGTENBERG, 2003). A auto-organização seria o compartilhamento do poder, o exercício da tomada de decisão coletiva pelos educandos, a possibilidade de cada indivíduo vivenciar diferentes papéis. É, por assim dizer, a construção de baixo para cima de relações que geram a libertação do coletivo e a superação da alienação do indivíduo, já que de acordo com Makarenko a escola deveria ser organizada como coletividade autogestionária, dirigindo, com o auxílio dos professores e da direção, o pleno desenvolvimento intelectual, psicológico e cultural de todas as crianças, inclusive no trabalho.

Para Makarenko o trabalho como princípio educativo não poderia ser tomado como concepção abstrata, pois deveria fazer parte de um sistema geral da coletividade, integrado ao estudo, como trabalho produtivo.

Makarenko acreditava ainda que era preciso retirar o caráter sagrado do trabalho, mostrando que o mesmo, isolado de um sistema geral de educação não influencia na formação de novos homens, mas ao contrário, dependendo do modo como o trabalho é realizado, pode resultar na negação da educação libertadora, acentuando os antigos vícios do passado: exploração, competição, individualismo e acumulação. Para ele a vida do coletivo dependia de uma luta política mais geral, para dar a seus educandos uma formação integral, como cidadãos e com isso, possibilitar a auto-gestão, ou autoorganização.

Por isso, a prática de ensino tinha que ter coerência com o método dialético de interpretação da realidade. Ao discutir esta questão Maurício Tragtenberg (2003), afirma que:

A realidade deve ser estudada como processo em desenvolvimento, como um processo dialético. Em consequiência, Pistrak prega o ensino pelo 'método dos complexos', pelo qual se estudam os fenômenos agrupados, enfatizando a interdependência transformadora, essência do método dialético (TRAGTENBERG, 2003, p. 12). 
O método dos complexos (também designado de sistema dos complexos) reflete a visão totalizadora da realidade, segundo o materialismo histórico dialético. Para esta concepção não há fenômenos isolados; cada fenômeno pode e deve ser perscrutado a partir de diversos aspectos, numa interdependência que deve levar a uma análise complexa. $\mathrm{O}$ método dos complexos, na prática, envolveria a discussão em torno de questões ou temas de pesquisa, levantando-se suas raízes históricas, políticas e econômicas. Tomemos como exemplo o tema "educação". Este pode ser analisado do ponto de vista do ensino escolar que, por sua vez, traz à tona uma série de questões fundamentais; por exemplo: quem ensina quem? O que é ensinado? Com que objetivo se ensina? Quem decide o que deve ser ensinado? Quem decide como se ensinar? Que papéis cabem ao professor e ao aluno? Quem avalia quem e com que objetivo? Qual a organização de conteúdos? Em que medida a experiência curricular reflete questões mais amplas da sociedade? É possível uma escola na qual os papéis de professor e de aluno sejam vivenciados por todos? Qual a relação entre ensino escolar e educação? E entre educação e política? De que modo aprendemos a ser a partir do processo educativo? Etc etc. Notemos que há aspectos que são centrais e aspectos que são periféricos, todos interligados, e cada questão pode ser vista de um ângulo macro ou micro. Qualquer que seja a direção dada à pesquisa e à análise, estas devem estar pautadas na idéia de superação de uma postura passiva diante da vida; superação que conduz ao entendimento de que somos sujeitos históricos e co-criadores de nossa existência, em seus diferentes aspectos.

É neste sentido que devemos discutir as propostas de educação do campo como propostas pedagógicas emancipatórias ou como um mecanismo de manutenção do status quo, à medida que, ao não admitir as categorias de totalidade e de contradição omitem o processo de luta de classes, inerentes ao modo de produção capitalista.

A pedagogia socialista de Pistrak e de Makarenko, ao centrar sua atenção na escola, e ao propor alternativas ao currículo do aluno abre ângulos novos em uma Rússia pósrevolução, mas, também, inspira experiências inovadoras nos movimentos sociais ligados ao campo. Em relação à educação do campo, a presença das idéias de Pistrak e Makarenko (e de outros educadores como, Krupskaya e Vygotsky) tem sido crescentes nos escritos e discussões que norteiam os documentos e diretrizes de propostas pedagógicas alternativas (RIBEIRO, 2009). Experiências como a Escola Itinerante (do Movimento dos Trabalhadores Rurais Sem Terra - MST), trazem marcas profundas dessas idéias ou, pelo menos, inspiradas em idéias de uma pedagogia socialista.

Há, entretanto, que se destacar a presença, bastante comum, de discursos e práticas pautadas em outros idiomas pedagógicos e, portanto, em vertentes políticas diferenciadas. A visão humanista libertadora de Paulo Freire foi e ainda é uma referência para os movimentos sociais que atuam no campo, tanto em relação à leitura de homem e de mundo quanto em relação à interação professor-aluno e prática em sala de aula. Freire traz à tona um discurso no qual, oprimidos e opressores (FREIRE, 1981), devem ser vistos de forma muito próxima àquela das análises socialistas de explorados e exploradores, e propõe uma "educação como prática da liberdade" (FREIRE, 1978), liberdade entendida em primeiro plano como a passagem de uma consciência ingênua para uma consciência crítica e a assunção do homem histórico, sujeito de sua própria história e transformador do mundo. Tanto as idéias quanto o trabalho político-pedagógico de Paulo Freire são, ainda hoje, tidos como exemplo de uma pedagogia de vanguarda que se contrapunha às pedagogias tradicionais.

Se é verdade que a pedagogia de Paulo Freire apresenta diversos pontos em comum com uma pedagogia socialista, é igualmente fato que seu discurso acerca dos mecanismos 
opressores da escola também se aproximam de vertentes estruturalistas, como as visões de Louis Althusser (1992) e de Pierre Bourdieu. O pensamento sociológico de Bourdieu, por sinal, também atrai olhares dos movimentos sociais ao tratar de conceitos como capital cultural, reprodução social e violência simbólica, auxiliando a desvelar os mecanismos de opressão sobre a classe trabalhadora (BOURDIEU e PASSERON, 1982). Paralelamente, notamos também alguns veios humanistas para além do pensamento freireano, muito mais inspirados em pedagogias renovadas ao entender o aluno como centro do processo de ensino e aprendizagem (ROGERS, 1978).

Este último autor, claramente de visão humanista-existencialista, embora pouco citado nos textos de propostas educacionais do campo, oferece a base para discursos humanizadores das relações entre professor e aluno. A rigor, na psicologia, discursos díspares como os de Rogers (visão humanista-existencialista), Vygotsky (visão sóciohistórica de inspiração marxista), Piaget (visão biológica estruturalista do desenvolvimento cognitivo) são, de longe, os mais citados, se não diretamente da fonte, pelo menos em termos de propostas de ação pedagógica restrita ou de interpretação de fenômenos psicológicos de aprendizagem. Em relação às propostas pedagógicas, o pensamento histórico-crítico de Dermeval Saviani também é lembrado, ao resgatar o papel político da escola de proporcionar o acesso aos conhecimentos científicos e sociais culturalmente acumulados pela humanidade.

Como se vê, temos um quadro diversificado e não é rara crítica de que muitos discursos e práticas de vanguarda se distanciam do discurso e prática socialistas e se aproximam de um ecletismo que descaracteriza a práxis emancipatória dos trabalhadores. No tocante a essa questão, entendemos que contribuições advindas de diferentes vertentes epistemológicas e políticas podem, sem dúvida, gerar um ecletismo desmobilizante e sem coerência interna. Porém, é necessário esclarecer o que estamos chamando de ecletismo que, a rigor, guarda diversos significados. Este termo pode se referir a uma busca metódica de conciliação de teorias diferentes. Pode também significar liberdade na busca e na escolha de pontos de vistas díspares, sem uma preocupação quanto à coerência. Pode igualmente se referir à tentativas de conciliar e utilizar pontos de vistas diversos e, por vezes, até mesmo contraditórios, esforçando-se por colocá-los em um sistema coeso. Por fim, na linguagem cotidiana, o termo pode se referir pejorativamente à miscelânea incoerente de pontos de vista claramente distintos e forçadamente utilizada com superficialidade, para a abordagem de uma questão ou um tema. Neste último sentido, dizse que um indivíduo é eclético quando, além da superficialidade e incoerência na análise, nota-se em seu discurso e/ou prática a presença de elementos e ranços de abordagens diferentes e, por vezes, antagônicas, quase sempre, com propósitos meramente pragmáticos.

\section{À guisa de conclusão.}

Embora o movimento "por uma educação do campo", tal qual o Movimento dos trabalhadores rurais sem terra - MST, em alguns momentos adotem uma postura idealista, conservadora, é perfeitamente factível observar que muitas de suas propostas revolucionárias, à medida que assumem posições marxianas ou de autores que buscaram sem Marx seus fundamentos teóricos, como Makarenko e Pistrak.

Acreditamos que para entender a realidade, os movimentos devem partir da premissa de que

são os indivíduos reais, a sua acção e as suas condições materiais de existência, quer se trate daquelas que encontrou já elaboradas 
quando do seu aparecimento das que ele próprio criou. Estas bases são portanto verificáveis por vias puramente empíricas. A primeira condição de toda a história humana é evidentemente a existência de seres humanos vivos. O primeiro estado real que encontramos é então constituído pela complexidade corporal desses indivíduos e as relações a que ela obriga com o resto da natureza. [...] Toda historiografia deve necessariamente partir dessas bases naturais e da sua modificação provocada pelos homens no decurso da história. (Marx e Engels, s.d., pp. 18-19)

É nessa perspectiva que Marx entende que ao produzirem os seus meios de existência, os homens produzem indiretamente a sua própria vida material, dado que para ele, a forma como os homens produzem esses meios depende em primeiro lugar da natureza, isto é, dos meios de existência já elaborados e que lhes é necessário reproduzir, uma vez que a forma como os indivíduos manifestam a sua vida reflete muito exatamente aquilo que são, ou seja, o que são coincide portanto com a sua produção, isto é, tanto com aquilo que produzem como com a forma como produzem. Aquilo que os indivíduos são depende, portanto, das condições materiais da sua produção (Marx e Engels, s.d., pp. 1819), determinando desta forma, a maneira como os movimentos entendem a realidade e nela atuam, buscando a sua transformação.

Assim como Makarenko e Pistrak, não podemos esquecer que Marx e Engels insistiram, em praticamente todas as obras, quanto a necessária articulação entre trabalho produtivo e formação intelectual, entendendo que esta relação deveria ser aberta a todos os educandos, e não somente aos filhos dos trabalhadores.

É importante ressaltar que, tomando por base o pensamento de Pistrak e Makarenko, o MST adota a defesa do trabalho como princípio educativo, no entanto, é preciso que se entenda que quando Marx e Engels propuseram que o trabalho produtivo fizesse parte da educação em geral, não se tratava de um mero ensino técnico, da aprendizagem de um ofício, mas de uma concepção de educação fundada na articulação entre o ensino com o trabalho produtivo.

Para os educadores marxistas, tanto quanto para Marx e Engels a expropriação dos saberes e conhecimentos técnicos dos trabalhadores que deu-se pela divisão do trabalho na produção, culminando com a separação do trabalho manual e do trabalho intelectual, resultado da separação dos trabalhadores dos instrumentos de trabalho, das matériasprimas e, enfim, dos próprios produtos produzidos, precisam ser retomados e colocados a serviço da classe trabalhadora, pois somente através dessa relação dialética entre trabalho braçal e trabalho intelectual é que se poderá processar a revolução, visando a superação das condições de vida e exploração do trabalho pelo capital, com a superação da estrutura de classes burguesa e de uma divisão social e técnica do trabalho que separa e aliena o trabalhador dos meios, processos e resultados da produção. 


\section{Bibliografia}

ALTHUSSER, L. Aparelhos ideológicos de Estado. (Trad. Walter Jose Evangelista). 6 ed. Rio de Janeiro: Graal, 1992. (Biblioteca de Ciências Sociais; v.25).

BOURDIEU, P. J.; PASSERON, J. C. A reprodução: elementos para uma teoria do sistema de ensino. (Trad. Reynaldo Bairao). 2 ed. Rio de Janeiro: Francisco Alves, 1982. (Serie Educacão em Questão).

CAMBI, Franco. História da Pedagogia. São Paulo: Editora da UNESP, 1999.

ENGELS, Friedrich. Anti-Dühring. Rio de Janeiro: Paz e Terra, 1979 (2a. ed.).

FÉLIX, C. E; MOREIRA, R. C.; SANTOS, C. R. Pistrak e o sistema do complexo na escola do trabalho. Revista Práxis Educacional, n. 3, 2007, pp. 211-229.

FREIRE, P. Educação como prática da liberdade. 8. ed. Rio de Janeiro: Paz e Terra, 1978. Pedagogia do oprimido. 9. ed. Rio de Janeiro: Paz e Terra, 1981.

FRIGOTTO, G. Trabalho, conhecimento, consciência e a educação do trabalhador: impasses teóricos e práticos. Em M. Gomez, G. Frigotto, M. Arruda, M. Arroyo e P. Nosella, Trabalho e Conhecimento: dilemas na educação do trabalhador (pp. 13-26). São Paulo: Cortez/Autores Associados, 1987.

LENINE, V.I.. Obras Escolhidas - Volume 1. São Paulo: Editora Alfa-Omega, 1982.

LOMBARDI, José Claudinei. Reflexões Sobre Educação e Ensino na Obra de Marx e Engels, Unicamp - Faculdade de Educação - 2010

MARX, K.. "Crítica ao Programa de Gotha". In: MARX, K. e F. Engels. Obras Escolhidas - Volume 2. São Paulo: Alfa-Omega, s/d., p. 203-225.

MARX, K.. "Prefácio da 1a. Edição". In: MARX, K.. O Capital - Livro 1, Volume 1, São Paulo: DIFEL, 1982 (7a. ed.), p. 3-7.

MARX, K.. Contribuição à Crítica da Economia Política. São Paulo: Martins Fontes, 1983 (2a. ed.).

MARX, K.. Teses sobre Feuerbach. In: MARX, K. e F. Engels. Obras Escolhidas Volume 3. São Paulo: Alfa-Omega, s/d., p. 208-210.

MARX, Karl e Engels, Friedrich. A Ideologia Alemã.... Lisboa: Editorial Presença; Brasil: Livraria Martins Fontes. [s.d.]. Volume I (311 p.) e Volume II (457 p.).

MARX, Karl e F. Engels. Obras Escolhidas - Volume 1. São Paulo: Alfa-Omega, s/d.

MARX, Karl e F. Engels. Obras Escolhidas - Volume 2. São Paulo: Alfa-Omega, s/d.

MARX, Karl e F. Engels. Obras Escolhidas - Volume 3. São Paulo: Alfa-Omega, s/d.

MARX, Karl e F. Engels. Obras Escolhidas - Volume 3. São Paulo: Alfa-Omega, s/d.

MARX, Karl. O capital. Crítica da Economia Política. Livro Primeiro. VOLUME I. O Processo de Produção do Capital. TOMO 2 (Capítulos XIII a XXV). São Paulo, Editora Nova Cultural, 1996. (Os Economistas).

PISTRAK, M. Fundamentos da escola do trabalho. (Trad. Daniel Aarão Reis Filho). São Paulo: Expressão popular, 2005. 
RIBEIRO, M. Trabalho e educação no movimento camponês: liberdade ou emancipação? Revista Brasileira de Educação, v. 14, n. 42, 2009, pp. 423-439.

SOARES, R. D. A concepção socialista da educação e os atuais paradigmas da qualificação para o trabalho: notas introdutórias. Educação \& Sociedade, n. 58, 1997, pp. $142-155$

TRAGTENBERG, M. Pistrak: uma pedagogia socialista. In: M. M. PISTRAK, Fundamentos da Escola do Trabalho. São Paulo: Brasiliense, 1981. p. 7-24

Notas:

\footnotetext{
${ }^{1}$ Bolsista CAPES. Doutoranda do Programa de Pós-Graduação em Educação, Universidade Federal de São Carlos, área de Fundamentos da Educação, sob orientação do Prof. Dr. Luiz Bezerra. E-mail: elianeidenl@bol.com.br

${ }^{2}$ Professor do Programa de Pós-Graduação em Educação da Universidade Federal de São Carlos, área de Fundamentos da Educação. E-mail: lbezerra@ufscar.br
}

Recebido em: $\quad 24 / 12 / 10$

Aprovado em: $\quad 20 / 02 / 11$ 